\title{
Mathematical Modeling and Applications for Concrete Carbonation
}

\author{
Ming-Te Liang \\ Professor, Department of Harbor and River Engineering, National Taiwan Ocean University, Keelung, Taiwan. \\ Shieng-Min Lin \\ Postgraduate, Department of Harbor and River Engineering, National Taiwan Ocean University, Keelung, Taiwan.
}

Follow this and additional works at: https://jmstt.ntou.edu.tw/journal

Part of the Civil and Environmental Engineering Commons

\section{Recommended Citation}

Liang, Ming-Te and Lin, Shieng-Min (2003) "Mathematical Modeling and Applications for Concrete Carbonation," Journal of Marine Science and Technology. Vol. 11: Iss. 1, Article 3.

DOI: $10.51400 / 2709-6998.2273$

Available at: https://jmstt.ntou.edu.tw/journal/vol11/iss1/3

This Research Article is brought to you for free and open access by Journal of Marine Science and Technology. It has been accepted for inclusion in Journal of Marine Science and Technology by an authorized editor of Journal of Marine Science and Technology. 


\section{Mathematical Modeling and Applications for Concrete Carbonation}

\section{Acknowledgements}

The authors would like to thank to the National Science Council of the R. O. C. for its financial support of this study under Contract NSC 89-2211-E-019-030. 


\title{
MATHEMATICAL MODELING AND APPLICATIONS FOR CONCRETE CARBONATION
}

\author{
Ming-Te Liang* and Shieng-Min Lin**
}

Key words: carbon dioxide, carbonation depth, diffusion coefficient, transport phenomena.

\section{ABSTRACT}

A new concept, carbon dioxide $\left(\mathrm{CO}_{2}\right)$ transport in concrete, is proposed in this paper to describe solute-transport processes. Using this concept, a new one-dimensional mathematical model was developed to describe the transport phenomena of carbon dioxide in concrete structures. By treating transport phenomena as a concrete carbonation process, a one-dimensional linear partial differential equation was derived based on the principle of mass balance and convective-dispersive equation and was found the analytical solution by the separation of variables and the Laplace transform methods combined with some substitution approaches. The concrete carbonation numerical results were determined using parameters, such as the diffusion coefficient, $\mathrm{CO}_{2}$ concentration, carbonation depth and time, occurring in concrete structures. The numerical results are presented to illustrate the practical applications of this model. These results are shown clearly that the proposed model may actually describe the concrete carbonation process chemically and physically. It is suggested that experiment should be performed to select suitable parameters for numerical simulations.

\section{INTRODUCTION}

Carbonation in concrete regularly involves a chemical reaction between carbon dioxide $\left(\mathrm{CO}_{2}\right)$ and the products of cement hydration. This reaction can result in a significant reduction in the $\mathrm{pH}$ of the pore solution due to the removal of the hydroxyl ions $\left(\mathrm{OH}^{-}\right)$, which may lead to steel depassivation and subsequent reinforcement corrosion. While carbonation in temperate climatic conditions may be related to environmental pollution, in arid and semiarid regions it may be accentuated by the elevated temperature and humidity.

Browne [3] used Fick's second diffusion law to make a family of curves for the chloride concentration

Paper Submitted 04/09/02, Accepted 02/27/03. Author for Correspondence: Ming-Te Liang.

* Professor, Department of Harbor and River Engineering, National Taiwan Ocean University, Keelung, Taiwan.

**Postgraduate, Department of Harbor and River Engineering, National Taiwan Ocean University, Keelung, Taiwan. with distance from the surface with time for different surface-chloride levels and chloride diffusion coefficients as a design nomogram. This nomogram can predict the service life of existing reinforced concrete structures. The literature is also rich in concrete carbonation investigations, aiming at developing empirical or semiempirical relations for the prediction of the rate of carbonation, and hence of the time required for depassivation of the reinforcing steel $[11,23,24,25,26$, $27,28,29,33,34,38]$ provided a general mathematical model of all physicochemical processes involved in concrete carbonation which was constructed and experimentally validated. Approximate solutions for this model allow quantitative prediction of the evolution of carbonation with time. This model helps in identifying those material and environmental parameters that affect the rate of carbonation and can be used for parametric studies of their effect on this rate.

Although these studies have provided much valuable information on the relationship between material and environmental factors, there are free of analytical solution [22] and are still many factors that have not yet been explored. This paper describes a theoretical study that is a one-dimentional linear diffusion equation with initial and boundary conditions. The mathematical model considers the relationships among unsteady state and diffusion, pore-water convective effect and chemical reaction and is shown in Table 1. The results of this study may be of importance to civil engineers and scholars attempting to develop programming standards and to researchers interested in the theoretical aspects of computer programming.

\section{THEORETICAL MODELING OF CONCRETE CARBONATION}

The rate at which carbon dioxide $\left(\mathrm{CO}_{2}\right)$ penetrates into concrete structures can be determined using several transport mechanisms. These mechanisms often act simultaneously on the concrete structures and may include such processes as convection, diffusion, dispersion, and first-order production [40] or decay. The general partial differential equation that relates these 
factors to a one-dimensional transport process can be written as

$$
R \frac{\partial C}{\partial t}=D_{s}-v \frac{\partial C}{\partial x}-K_{T} C-r
$$

where $C$ is the concentration of carbon dioxide, $D_{s}$ is the diffusion coefficient, $R$ is the retardation factor (dimensionless), $v$ is the pore-water velocity, $K_{T}$ is the rate constant for first-order decay at a given temperature $T, r$ is the rate constant for zero-order production
[40], $x$ is space and $t$ is time. Equation (1) or the appropriate simplification has also found widespread application in soil science, chemical and environmental engineering, and water resources. A similar form has also been proposed by Tchobanoglons [36] and Chen et al. [5] for use in constructed wetlands.

Equation (1) describes the one-dimensional transport phenomena of concrete carbonation. If $R=1$ (This means that the carbonation phenomenon is only concerned in this present study) and $r=0$ (This means that

Table 1. A catalogue of one-dimensional linear diffusion equations

\begin{tabular}{|c|c|c|}
\hline Governing equations & Description & References \\
\hline $\begin{array}{l}1 \operatorname{PDE} \frac{\partial C}{\partial t}=D_{s} \frac{\partial^{2} C}{\partial x^{2}} \\
\operatorname{IC~} C(x, 0)=C_{i} \\
\operatorname{BC~} C(0, t)=C_{s} \\
C(L, t)=C_{f}\end{array}$ & $\begin{array}{l}\text { Consider the relationships between unsteady, } \frac{\partial C}{\partial t} \text {, } \\
\text { and diffusion, } D_{s} \frac{\partial^{2} C}{\partial x^{2}} \text {. }\end{array}$ & {$[3,6,7,9,12,16,17,37,38,42]$} \\
\hline $\begin{array}{l}2 \operatorname{PDE} \frac{\partial C}{\partial t}=D_{s} \frac{\partial^{2} C}{\partial x^{2}}-K_{T} C \\
\operatorname{IC~} C(x, 0)=C_{i} \\
\operatorname{BC~} C(0, t)=C_{s} \\
C(L, t)=C_{f}\end{array}$ & $\begin{array}{l}\text { Consider the relationships among unsteady, } \frac{\partial C}{\partial t}, \\
\text { and diffusion, } D_{s} \frac{\partial^{2} C}{\partial x^{2}} \text {, and chemical reaction, } K_{T} C \text {. }\end{array}$ & {$[19,37]$} \\
\hline $\begin{array}{l}3 \mathrm{PDE} \frac{\partial C}{\partial t}=D_{s} \frac{\partial^{2} C}{\partial x^{2}}-r \\
\mathrm{IC} C(x, 0)=0 \\
\operatorname{BC~} C(0, t)=C_{s} \\
\frac{\partial C}{\partial n}(0, t)=0\end{array}$ & $\begin{array}{l}\text { Consider the relationships among unsteady, } \frac{\partial C}{\partial t} \text {, anc } \\
\text { diffusion, } D_{s} \frac{\partial^{2} C}{\partial x^{2}} \text {, and rate constant for zero-order } \\
\text { production,. } r\end{array}$ & {$[30,32]$} \\
\hline $\begin{array}{l}4 \operatorname{PDE} \frac{\partial C}{\partial t}=D_{s} \frac{\partial^{2} C}{\partial x^{2}}-v \frac{\partial C}{\partial x} \\
\operatorname{IC~} C(x, 0)=0 \\
\operatorname{BC~} C(0, t)=C_{s} \\
C(L, t)=0\end{array}$ & $\begin{array}{l}\text { Consider the relationships among unsteady, } \frac{\partial C}{\partial t} \text {, anc } \\
\text { diffusion, } D_{s} \frac{\partial^{2} C}{\partial x^{2}} \text { and pore-water convective effect, } \\
v \frac{\partial C}{\partial x} \text {. }\end{array}$ & {$[35]$} \\
\hline $\begin{array}{l}5 \text { PDE } \\
\frac{\partial C}{\partial t}=D_{s} \frac{\partial^{2} C}{\partial x^{2}}-v \frac{\partial C}{\partial x}-K_{T} C \\
\operatorname{IC~} C(x, 0)=C_{i} \\
\operatorname{BC~} C(0, t)=C_{s} \\
C(L, t)=C_{f}\end{array}$ & $\begin{array}{l}\text { Consider the relationships among unsteady, } \frac{\partial C}{\partial t} \text {, anc } \\
\text { diffusion, } D_{s} \frac{\partial^{2} C}{\partial x^{2}} \text {, pore-water convective effect, } \\
v \frac{\partial C}{\partial x} \text {, and chemical reaction, } K_{T} C \text {. }\end{array}$ & {$[5,18,31]$} \\
\hline $\begin{array}{l}6 \mathrm{PDE} \\
\frac{\partial C}{\partial t}=D_{s} \frac{\partial^{2} C}{\partial x^{2}}-v \frac{\partial C}{\partial x}-K_{T} C-r \\
\mathrm{IC} C(x, 0)=C_{i} \\
\mathrm{BC} C(0, t)=C_{s} \\
C(L, t)=C_{f}\end{array}$ & $\begin{array}{l}\text { Consider the relationships among unsteady, } \frac{\partial C}{\partial t} \text {, anc } \\
\text { diffusion, } D_{s} \frac{\partial^{2} C}{\partial x^{2}} \text {, pore-water convective effect, } \\
v \frac{\partial C}{\partial x} \text {, chemical reaction, } K_{T} C \text {, and rate constant for } \\
\text { zero-order production,. } r\end{array}$ & {$[5,36]$} \\
\hline
\end{tabular}

Remark: $C(x, t)$ is the concentration of $\mathrm{CO}_{2}$ at space $x$ time $t, C_{i}, C_{s}$ and $C_{f}$ are the initial concentration of $C \mathrm{O}_{2}$ in concrete, on the surface of concrete structure, and at the interface between concrete and steel, respectively, $D_{s}$ is the diffusion coefficient, $K_{T}$ is the rate constant for first-order decay at a given temperature $T, v$ is the pore-water velocity, $r$ is the rate constant for zeroorder production, $\mathrm{x}$ is space and $\mathrm{t}$ is time. $n$ represents the normal direction from the common boundary. 
in the carbonated zone the reduction of concrete absorbed $\mathrm{CO}_{2}$ has been finished, i.e., the absorbed $\mathrm{CO}_{2}$ mass pen unit volume per unit time equal zero), Eq. (1) becomes

$$
\frac{\partial C}{\partial t}=D_{s} \frac{\partial^{2} C}{\partial x^{2}}-v \frac{\partial C}{\partial x}-K_{T} C
$$

Initial and boundary conditions are

$$
\begin{aligned}
& C(x, 0)=C_{i} \\
& C(0, t)=C_{s} \\
& C(L, t)=C_{f}
\end{aligned}
$$

where $C_{i}, C_{s}$ and $C_{f}$ are the initial concentration of carbon dioxide in concrete, on the surface of the concrete structures, and at the interface between the concrete and steel, respectively. $L$ is the concrete cover thickness on the reinforcing steel.

In order to solve the concrete carbonation problem modeled by Eqs. (2)-(5), first of all one assumes

$$
C(x, t)=e^{\alpha x+\beta t} \phi(x, t)
$$

where $\alpha$ and $\beta$ are the constant parameters, and $\phi(x, t)$ is a new function of $\mathrm{CO}_{2}$ concentration.

Substitution Eq. (6) into Eq. (2) gives

$$
\frac{\partial \phi}{\partial t}=D_{s} \frac{\partial^{2} \phi}{\partial x^{2}}+\left(2 \alpha D_{s}-v\right) \frac{\partial \phi}{\partial x}+\left(D_{s} \alpha^{2}-v \alpha-K_{T}-\beta\right) \phi
$$

In order to reduce Eq. (7) as a standard form of the one-dimensional diffusion equation, the coefficients of the second and third terms on the right-hand side should be equal to zero, i.e.,

$$
\begin{aligned}
& 2 \alpha D_{s}-v=0 \\
& D_{s} \alpha^{2}-v \alpha-K_{T}-\beta=0
\end{aligned}
$$

From Eq. (8), one has

$$
\alpha=\frac{v}{2 D_{s}}
$$

Substituting Eq. (10) into Eq. (9), one obtains

$$
\beta=-\frac{v^{2}}{4 D_{s}}-K_{T}
$$

The solution methods of Separation of Variables and Laplace transform are described in the following.

\section{Separation of Variables Method}

Now the problem formulated by Eqs. (2)-(5) changes into the control equation with initial and boundary conditions

$$
\begin{aligned}
& \frac{\partial \phi}{\partial t}=D_{s} \frac{\partial^{2} \phi}{\partial x^{2}} \\
& \phi(x, 0)=C_{i} e^{-\alpha x} \\
& \phi(0, t)=C_{s} e^{-\beta t} \\
& \phi(L, t)=C_{f} e^{-\alpha L-\beta t}
\end{aligned}
$$

For solving the problem of concrete carbonation modeled by Eqs. (12)-(15), one assumes

$$
\phi(x, t)=\Phi(x, t)+\varphi(x)
$$

Substitution Eq. (16) into Eqs. (12), (14), and (15) yields

$$
\begin{aligned}
& \frac{\partial \Phi}{\partial t}=D_{s} \frac{\partial^{2} \Phi}{\partial x}+D_{s} \varphi^{\prime \prime}(x) \\
& \phi(0, t)=\Phi(0, t)+\varphi(0)=C_{s} e^{-\beta t} \\
& \phi(L, t)=\Phi(L, t)+\varphi(L)=C_{f} e^{-\alpha L-\beta t}
\end{aligned}
$$

One chooses $\varphi(x)$ as a solution of the problem

$\varphi^{\prime \prime}(x)=0 ; \varphi(0)=C_{s} e^{-\beta t}, \varphi(L)=C_{f} e^{-\alpha L-\beta t}$

Integrating twice to $\varphi^{\prime \prime}(x)=0$, one obtains

$\varphi(x)=A x+B$

where A and B are integral constants.

Putting the boundary conditions in Eq. (20) into Eq. (21), one obtains

$$
A=\frac{1}{L}\left(C_{f} e^{-\alpha L-\beta t}-C_{s} e^{-\beta t}\right) \text { and } B=C_{i} e^{-a x} .
$$

Thus, one has

$$
\varphi(x)=\frac{1}{L}\left(C_{f} e^{-\alpha L-\beta t}-C_{s} e^{-\beta t}\right) x+C_{s} e^{-\beta t}
$$

With the choice of $\varphi(x)$, the initial and boundary value problem for $\Phi(x, t)$ is formulated as

$$
\begin{aligned}
& \frac{\partial \Phi}{\partial t}=D_{s} \frac{\partial^{2} \Phi}{\partial x^{2}}, 0 \leq x \leq L, t>0 \\
& \Phi(0, t)=0 \\
& \Phi(L, t)=0 \\
& \Phi(x, 0)=\phi(x, 0)-\varphi(0)=C_{i} e^{-\alpha x}-\varphi(x)=f(x)
\end{aligned}
$$


In order to solve the concrete carbonation problem modeled by Eqs. (23)-(26), the separation of variables method is used, i. e.,

$$
\Phi(x, t)=X(x) T(t)
$$

where $X(x)$ and $\mathrm{T}(\mathrm{t})$ are the functions of the independent variables of $x$ and $t$, respectively. Substituted Eq. (27) into Eq. (23), one obtains

$$
X \dot{T}=D_{s} X^{\prime} T
$$

where the superscribe dot and prime indicate $T$ and $X$ of the first and second partial derivative with respect to $t$ and $x$, respectively.

Equation (28) can be written as

$$
\frac{X^{\prime \prime}}{X}=\frac{\dot{T}}{D_{s} T}=k
$$

where $k$ is an unknown constant to be determined.

Equation (29) can be rewritten as two ordinary differential equations

$$
\begin{aligned}
& X^{\prime \prime}-k X=0 \\
& \dot{T}-D_{s} k T=0
\end{aligned}
$$

At the present, one first solves Eq. (30). However, from Eqs. (24), (25) and (27), one knows

$$
\begin{aligned}
& \Phi(0, t)=X(0) T(t)=0 \\
& \Phi(L, t)=X(L) T(t)=0
\end{aligned}
$$

If $T(t)$ in Eqs. (32) and (33), then $\Phi(x, t)$ should be a trivial solution. This is not an interesting result. Hence, under the condition of $T(t) \neq 0$, one discovers

$$
\begin{aligned}
& X(0)=0 \\
& X(L)=0
\end{aligned}
$$

If $k=0$ in Eq. (30), then Eq. (30) becomes

$$
X^{\prime \prime}(x)=0
$$

After doubling the integral, one has

$$
X(x)=D x+E
$$

where $D$ and $E$ are integral constants.

Substituting Eqs. (34) and (35) into Eq. (37), one finds $D=E=0$. Moreover, $X(x)=0$. This is a trivial solution. $\Phi(x, t)$ is a corresponding trivial solution.
If $k>0$, then set $k=p^{2}$, where $p>0$. Equation (30) is written as

$$
X^{\prime \prime}-p^{2} X=0
$$

The general solution for Eq. (38) is

$$
X(x)=F e^{p x}+G e^{-p x}
$$

where $F$ and $G$ are constants.

Placing Eqs. (34) and (35) into Eq. (39), one has $F$ $=G=0$, i. e. $X(x)=0$. This is again a trivial solution. $\Phi(x, t)$ is again a corresponding trivial solution.

If $k<0$, then put $k=-p^{2}$, where $p>0$. Equation (30) is changed as

$$
X^{\prime \prime}+p^{2} X=0
$$

The general solution for Eq. (40) is

$$
X(x)=H \cos (p x)+I \sin (p x)
$$

Substituting Eq. (34) into Eq. (41), one discovers $H=0$. Placing Eq. (35) into Eq. (41), one obtains

$$
I \sin (p x)=0
$$

If $I=0$, then $X(x)=0$, i.e., $\Phi(x, t)=0$. This is a trivial solution. One puts $I=0$ into the discard. Now consider

$$
\sin (p x)=0
$$

From Eq. (43), one knows

$$
p L=n \pi, p>0, n=1,2,3 \ldots
$$

Thus, for each positive integer $n$, one obtains the eigenvalue of the initial and boundary value problem for $\Phi(x, t)$, i.e.,

$$
k_{n}=\frac{n^{2} \pi^{2}}{L^{2}}
$$

The corresponding eigenfunction is

$$
X_{n}(x)=I_{n} \sin \left(\frac{n \pi x}{L}\right)
$$

At present, one should solve Eq. (31). Equation (31) is changed into

$$
\dot{T}+\frac{n^{2} \pi^{2} D_{s}}{L^{2}} T=0, n=1,2,3 \ldots
$$

The solution for Eq. (47) is

$$
T_{n}=J_{n} \exp \left(-\frac{n^{2} \pi^{2} D_{s} t}{L^{2}}\right)
$$


where $J_{n}$ is a constant.

Substituting Eqs. (47) and (48) into Eq. (27), one obtains

$$
\begin{aligned}
& \Phi_{n}(x, t)=K_{n} \sin \left(\frac{n \pi x}{L}\right) \exp \left(-\frac{n^{2} \pi^{2} D_{s} t}{L^{2}}\right) \\
& n=1,2,3 \ldots
\end{aligned}
$$

where $K_{n}=I_{n} J_{n}$ is a constant.

Since Eq. (23) is linear and homogeneous, one obtains the solution using the principle of superposition

$$
\Phi_{n}(x, t)=\sum_{n=1}^{\infty} K_{n} \sin \left(\frac{n \pi x}{L}\right) \exp \left(-\frac{n^{2} \pi^{2} D_{s} t}{L^{2}}\right)
$$

Placing Eq. (26) into Eq. (50), one has

$\Phi_{n}(x, 0)=f(x)=C_{i} e^{-\alpha x}-\varphi(x)=\sum_{n=1}^{\infty} K_{n} \sin \left(\frac{n \pi x}{L}\right)$

Eq. (51) is the Fourier sine series. Thus, one chooses

$$
\begin{aligned}
K_{n} & =\frac{2}{L} \int_{0}^{L} f(x) \sin \left(\frac{n \pi x}{L}\right) d x \\
& =\frac{2}{L} \int_{0}^{L}\left[C_{i} e^{-\alpha x}-\varphi(x)\right] \sin \left(\frac{n \pi x}{L}\right) d x
\end{aligned}
$$

Substituting Eq. (52) into Eq. (50), one has

$$
\begin{aligned}
& \Phi_{n}(x, t)=\frac{2}{L} \sum_{n=1}^{\infty}\left\{\int _ { 0 } ^ { L } \left[C_{i} e^{-\alpha \xi}\right.\right. \\
& \left.-\varphi(\xi)] \sin \left(\frac{n \pi \xi}{L}\right) d \xi\right\} \sin \left(\frac{n \pi x}{L}\right) \exp \left(\frac{-n^{2} \pi^{2} D_{s} t}{L^{2}}\right)
\end{aligned}
$$

The substitution of Eqs. (22)and (53) into Eq. (16) yields

$$
\begin{aligned}
& \Phi_{n}(x, t)=\frac{2}{L} \sum_{n=1}^{\infty}\left\{\int _ { 0 } ^ { L } \left[C_{i} e^{-\alpha \xi}\right.\right. \\
& \left.-\varphi(\xi)] \sin \left(\frac{n \pi \xi}{L}\right) d \xi\right\} \sin \left(\frac{n \pi x}{L}\right) \exp \left(\frac{-n^{2} \pi^{2} D_{s} t}{L^{2}}\right) \\
& +\frac{1}{L}\left(C_{f} e^{-\alpha L-\beta t}-C_{s} e^{-\beta t}\right) x+C_{s} e^{-\beta t}
\end{aligned}
$$

Finally, putting Eq. (54) into Eq. (6), one obtains the analytical solution for the original problem

$$
\begin{aligned}
& C(x, t)=a^{\alpha x+\beta t}\left\{\frac { 2 } { L } \sum _ { n = 1 } ^ { \infty } \left\{\int _ { 0 } ^ { L } \left[C_{i} e^{-\alpha \xi}\right.\right.\right. \\
& \left.-\varphi(\xi)] \sin \left(\frac{n \pi \xi}{L}\right) d \xi\right\} \sin \left(\frac{n \pi x}{L}\right) \exp \left(\frac{-n^{2} \pi^{2} D_{s} t}{L^{2}}\right) \\
& \left.+\frac{1}{L}\left(C_{f} e^{-\alpha L-\beta t}-C_{s} e^{-\beta t}\right) x+C_{s} e^{-\beta t}\right\}
\end{aligned}
$$

\section{Laplace Transform Method}

Now the problem formulated by Eqs. (2)-(5) changes to the following governing equation with initial and boundary conditions

$$
\begin{aligned}
& \frac{\partial \phi}{\partial t}=D_{s} \frac{\partial^{2} \phi}{\partial x^{2}} \\
& \phi(x, 0)=C_{i} e^{-\alpha x} \\
& \phi(0, t)=C_{s} e^{-\beta t} \\
& \phi(L \rightarrow \infty, t)=0 \quad\left(\phi(L, t)=C_{f} e^{-\alpha L-\beta t}\right)
\end{aligned}
$$
obtains

Taking the Laplace transform of Eq. (56), one

$$
\Phi^{\prime \prime}-\frac{s}{D_{s}} \Phi=-\frac{C_{i}}{D_{s}} e^{-\alpha x}
$$

The complementary function of Eq. (60) is

$\Phi_{c}(x, s)=c_{1} e^{\sqrt{\frac{s}{D_{s}}} x}+c_{2} e^{-\sqrt{\frac{s}{D_{s}}} x}$

One now assumes that the particular integral of Eq. (60) can be expressed by

$$
\Phi_{p}(x, s)=m e^{-\alpha x}
$$

where $m$ is a constant.

Substituting Eq. (62) into Eq. (60), one has

$$
m=\frac{C_{i}}{s-\frac{v^{2}}{4 D_{s}}}
$$

Therefore, the general solution to Eq. (60) is given by

$$
\begin{aligned}
\Phi(x, s) & =\Phi_{c}(x, s)+\Phi_{p}(x, s)=c_{1} e^{\sqrt{\frac{s}{D_{s}}} x}+c_{2} e^{-\sqrt{\frac{s}{D_{s}}} x} \\
& +\frac{C_{i}}{s-\frac{v^{2}}{4 D_{s}}} e^{-\alpha x}
\end{aligned}
$$

By taking the Laplace transform of Eqs. (58) and (59) and using Eq. (64), one obtains

$$
\begin{aligned}
& \Phi(0, s)=\frac{C_{s}}{s+\beta}=c_{1}+c_{2}+\frac{C_{i}}{s-\frac{v^{2}}{4 D_{s}}} \\
& \Phi(\infty, s)=0=c_{1} e \sqrt{\frac{s}{D_{s}}} \infty
\end{aligned}
$$

In order to obtain a bounded solution to Eq. (60), let $c_{1}=0$ in Eq. (66). Thus, one obtains

$$
c_{2}=\frac{C_{s}}{s+\beta}-\frac{C_{i}}{s-\frac{v^{2}}{4 D_{s}}}
$$

Hence Eq. (64) can be written as 


$$
\Phi(x, s)=\left(\frac{C_{s}}{s+\beta}-\frac{C_{i}}{s-\frac{v^{2}}{4 D_{s}}}\right) e^{-\sqrt{\frac{s}{D_{s}}} x}+\frac{C_{i}}{s-\frac{v^{2}}{4 D_{s}}} e^{-\alpha x}
$$

in terms of $C_{i}$ and $C_{s}$. The following inverse Laplace transforms can be found from the table [1]

$$
\begin{aligned}
& L^{-1}\left\{e^{-\sqrt{\frac{s}{D_{s}}} x}\right\}=\frac{x}{2 \sqrt{\pi D_{s} t^{3}}} e^{-\frac{x^{2}}{4 D_{s} t}} \\
& L^{-1}\left\{\frac{C_{s}}{s-\frac{v^{2}+4 K_{T} D_{s}}{4 D_{s}}}\right\}=C_{s} e^{\frac{v^{2}+4 K_{T} D_{s}}{4 D_{s}} t} \\
& L^{-1}\left\{\frac{C_{i}}{s-\frac{v^{2}}{4 D_{s}}}\right\}=C_{i} e^{\frac{v^{2}}{4 D_{s}} t} \\
& L^{-1}\left\{\frac{C_{i}}{s-\frac{v^{2}}{4 D_{s}}} e^{\frac{-v}{2 D_{s}} x}\right\}=C_{i} e^{\frac{v^{2}}{4 D_{s}} t} \cdot e^{\frac{-v}{2 D_{s}} x}=C_{i} e^{\frac{v^{2}}{4 D_{s}} t-\frac{v}{2 D_{s}} x}
\end{aligned}
$$$$
L^{-1}\left\{\left(\frac{C_{s}}{s-\frac{v^{2}+4 K_{T} D_{s}}{4 D_{s}}}-\frac{C_{i}}{s-\frac{v^{2}}{4 D_{s}}}\right) e^{-\sqrt{\frac{s}{D_{s}}} x}\right\}
$$$$
=\int_{0}^{t} \frac{x}{2 \sqrt{\pi D_{s} \tau^{3}}} e^{-\frac{x^{2}}{4 D_{s} \tau}}\left(C_{s} e^{\frac{v^{2}+4 K}{4 D_{s} D_{s}}(t-\tau)}\right.
$$$$
\left.-C_{i} e^{\frac{v^{2}}{4 D_{s} \tau}(t-\tau)}\right) d \tau
$$

Note that Eq. (73) has used the convolution theorem. Taking the Laplace transform to Eq. (68), one obtains

$$
\begin{aligned}
\phi(x, t) & =\int_{0}^{t} \frac{x}{2^{2} \sqrt{\pi D_{s} \tau^{3}}} e^{-\frac{x^{2}}{4 D_{s} \tau}}\left(C_{s} e^{\frac{v^{2}+4 K}{4 D_{s} D_{s}}(t-\tau)}\right. \\
& \left.-C_{i} e^{\frac{v^{2}}{4 D_{s} \tau}(t-\tau)}\right) d \tau+C_{i} e^{\frac{v^{2}}{4 D_{s}} t-\frac{v}{2 D_{s}} x}
\end{aligned}
$$

Finally, inserting Eq. (74) into Eq. (5), one obtains the analytical solution for the original problem

$$
\begin{aligned}
& C(x, t)=e^{\frac{v}{2 D_{s}} x-\frac{v^{2}+4 K_{T} D_{s}}{4 D_{s}} t} \int_{0}^{t} \frac{x}{2 \sqrt{\pi D_{s} \tau^{3}}} e^{-\frac{x^{2}}{4 D_{s} \tau}} \\
& \left(C_{s} e^{\frac{v^{2}+4 K_{T} D_{s}}{4 D_{s}}(t-\tau)}-C_{i} e^{\frac{v^{2}}{4 D_{s}}(t-\tau)}\right) d \tau+C_{i} e^{-K_{T} t}
\end{aligned}
$$

\section{NUMERICAL RESULTS AND PPLICATIONS}

The computer package "Mathematica" [41] was used to show the closed form solution of Eqs. (55) and (75). The relationships between carbonation depth and time at $D_{s}=10^{-11} \mathrm{~m}^{2} / \mathrm{s}, D_{s}=10^{-12} \mathrm{~m}^{2} / \mathrm{s}$ and $D_{s}=$ $10^{-13} \mathrm{~m}^{2} / \mathrm{s}$ are displayed in Figs. 1 to 3, respectively. The concentration-time relationships at $D_{s}=10^{-11} \mathrm{~m}^{2} / \mathrm{s}, D_{s}=$ $10^{-12} \mathrm{~m}^{2} / \mathrm{s}$ and $D_{s}=10^{-13} \mathrm{~m}^{2} / \mathrm{s}$ are manifested in Figs. 4 to 6 , respectively. The relation between concentration and carbonation depth at $D_{s}=10^{-11} \mathrm{~m}^{2} / \mathrm{s}, D_{s}=10^{-12} \mathrm{~m}^{2} / \mathrm{s}$ and $D_{s}=10^{-13} \mathrm{~m}^{2} / \mathrm{s}$ are disclosed in Figs. 7 to 9 , respectively. The diffusion coefficient-time relationships at $x=0.01 \mathrm{~m}, x=0.02 \mathrm{~m}$ and $x=0.03 \mathrm{~m}$ are shown in Figs. 10 to 12, respectively.

Assume that a reinforced concrete structure has $C_{i}=0.0 \mathrm{~g} / \mathrm{m}^{3}, C_{s}=0.7 \mathrm{~g} / \mathrm{m}^{3}, C_{f}=0.2 \mathrm{~g} / \mathrm{m}^{3}, v=$ $10^{-12} \mathrm{~m} / \mathrm{s}, K_{T}=10^{-10} 1 / \mathrm{s}$, and $L=0.05 \mathrm{~m}$. From Fig. 1 , one knows the carbonation depth $x=0.025 \mathrm{~m}$ after $t=688$ days with $C(x, t)=0.35 \mathrm{~g} / \mathrm{m}^{3}$ and $D_{s}=10^{-11} \mathrm{~m}^{2} / \mathrm{s}$. For $D_{s}$ $=10^{-13} \mathrm{~m}^{2} / \mathrm{s}$ and $C(x, t)=0.3 \mathrm{~g} / \mathrm{m}^{3}$, one needs $t=8000$ days at $x=0.01 \mathrm{~m}$ from Fig. 6 . If one knows $D_{s}=10^{-12}$ $\mathrm{m}^{2} / \mathrm{s}$ and $C(x, t)=0.4 \mathrm{~g} / \mathrm{m}^{3}$, one obtains $x=0.014 \mathrm{~m}$ after $t=3000$ days from Fig. 8 .

\section{DISCUSSION}

The numerical results obtained from both the Laplace transform and separation of variables methods are compared as shown in Figs. 1 to 12. Intuitively, as the same concrete carbonation problem, however, the numerical results reveal the obvious differences between the Laplace transform method and the separation of variables method. This is due to $C_{f}=0.2 \mathrm{~g} / \mathrm{m}^{3}$ without appearing in Eq. (75) but with in Eq. (55). This means that the value of $C_{f}$ is varied with time for the Laplace transform method while $C_{f}$ is the constant value as just

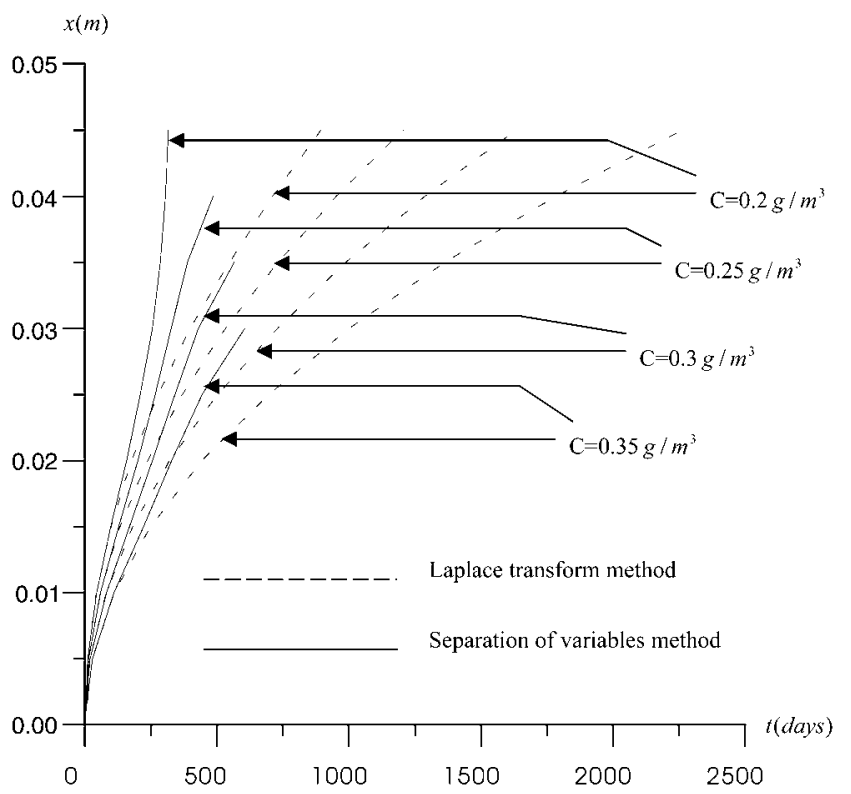

Fig. 1. Relationship between carbonation depth and time at $D_{s}=10^{-11} \mathrm{~m}^{2} / \mathrm{s}$. 
given for the separation of variables method.

Guirguis [10] and Mallett [21] pointed out that a general expression for the depth of carbonation, $x$, to the quality of concrete and time of exposure, $t$, can be given in the form

$$
x=K \sqrt{t}
$$

where $K$ is related to the rate of carbonation and is dependent upon the properties of the concrete.

Now consider the one-dimensional diffusion equa-

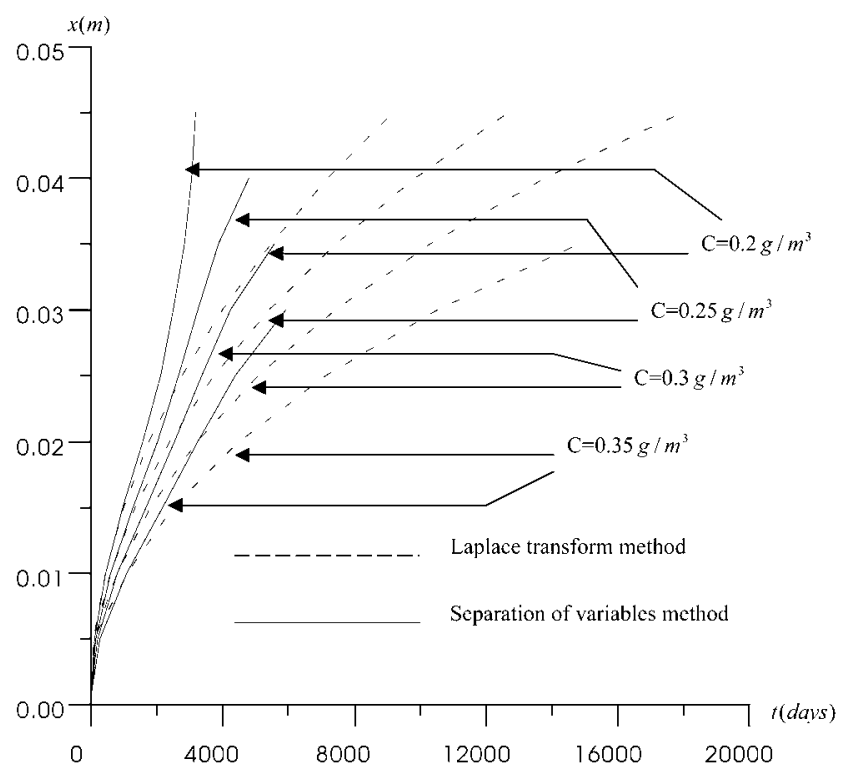

Fig. 2. Relationship between carbonation depth and time at $D_{s}=10^{-12} \mathrm{~m}^{2} / \mathrm{s}$.

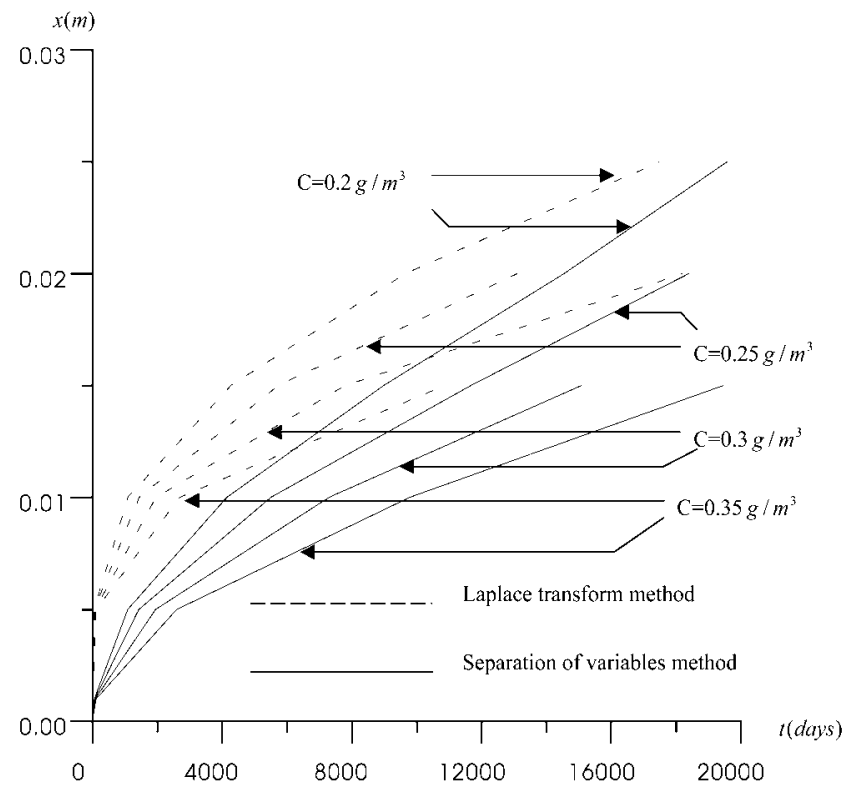

Fig. 3. Relationship between carbonation depth and time at $D_{s}=10^{-13} \mathrm{~m}^{2} / \mathrm{s}$. tion with initial and boundary conditions

$$
\begin{aligned}
& \frac{\partial C}{\partial t}=D_{s} \frac{\partial^{2} C}{\partial x^{2}} \\
& C(x, 0)=C_{i} \\
& C(0, t)=C_{s}, C(L, t)=C_{f}=C_{i}
\end{aligned}
$$

Taking the Laplace transform method, the analyti-

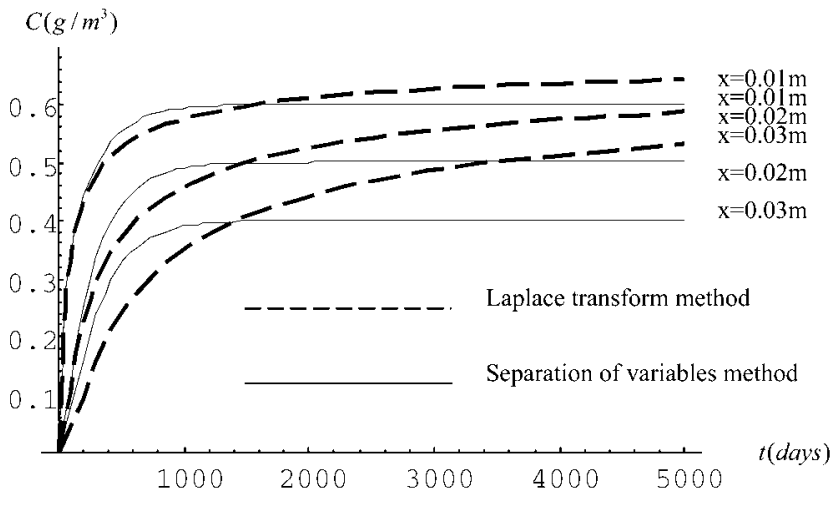

Fig. 4. Concentration-time relationships at $D_{s}=10^{-11} \mathrm{~m}^{2} / \mathrm{s}$.

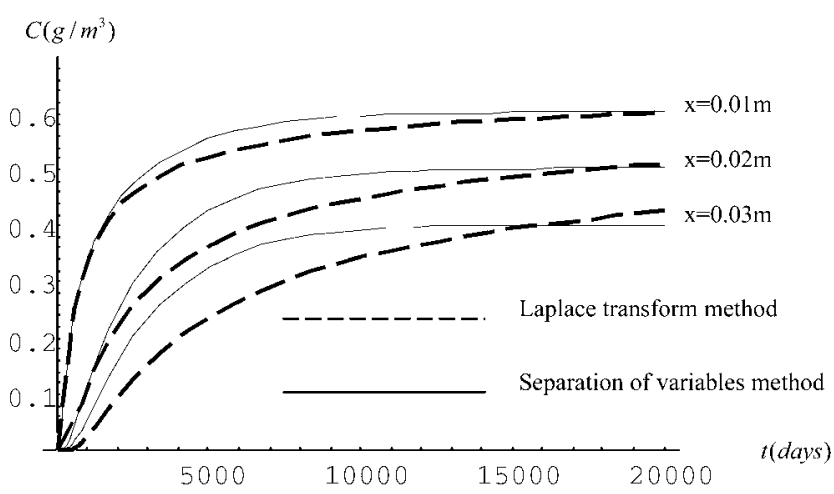

Fig. 5. Concentration-time relationships at $D_{s}=10^{-12} \mathrm{~m}^{2} / \mathrm{s}$.

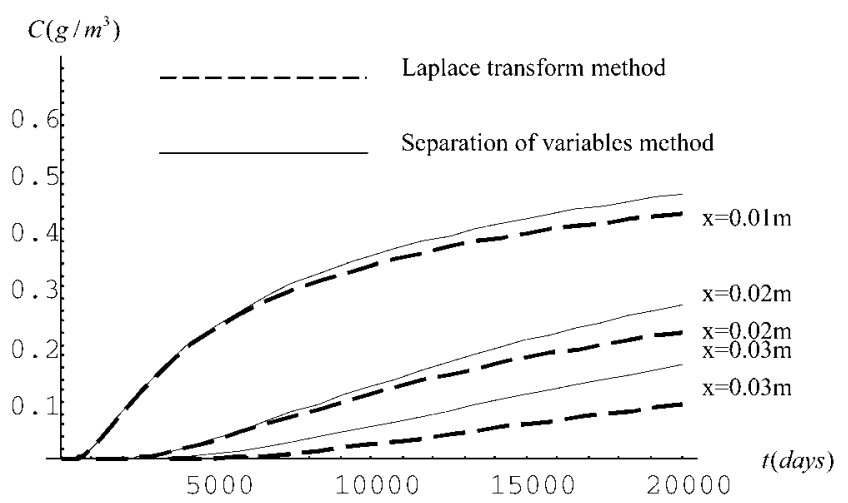

Fig. 6. Concentration-time relationships at $D_{s}=10^{-13} \mathrm{~m}^{2} / \mathrm{s}$. 
cal solution for Eq. (77) is

$$
C(x, t)=C_{i}+\left(C_{s}-C_{i}\right) \operatorname{erfc}\left(\frac{x}{\sqrt{4 D_{s} t}}\right)
$$

where $\operatorname{erfc}(\bullet)$ is the complementary error function.

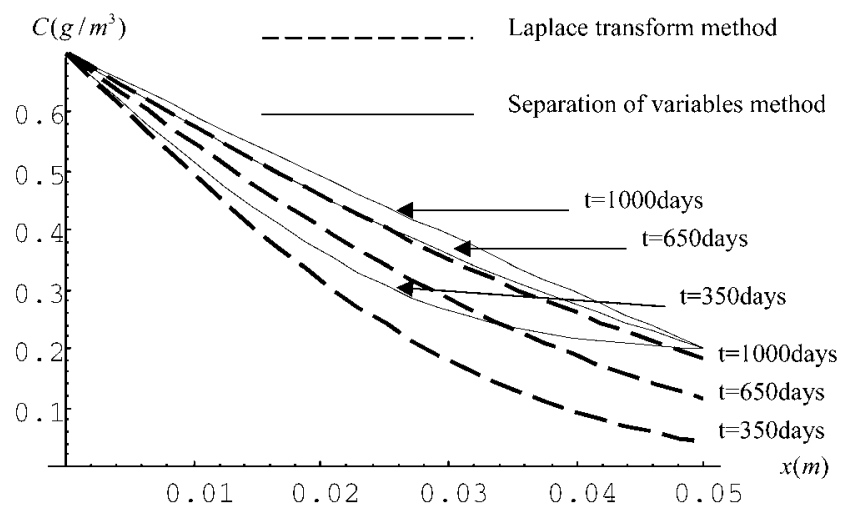

Fig. 7. Relation between concentration and carbonation depth at $D_{s}=$ $10^{-11} \mathrm{~m}^{2} / \mathrm{s}$.

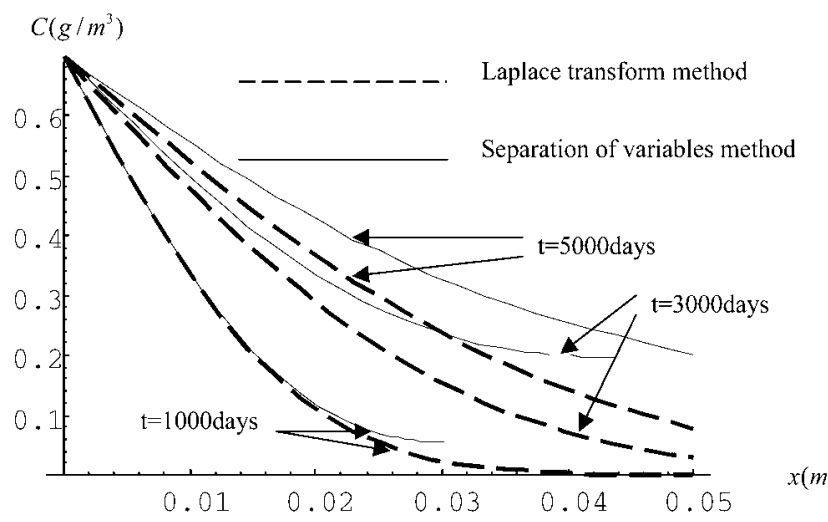

Fig. 8. Relation between concentration and carbonation depth at $D_{s}=$ $10^{-12} \mathrm{~m}^{2} / \mathrm{s}$.

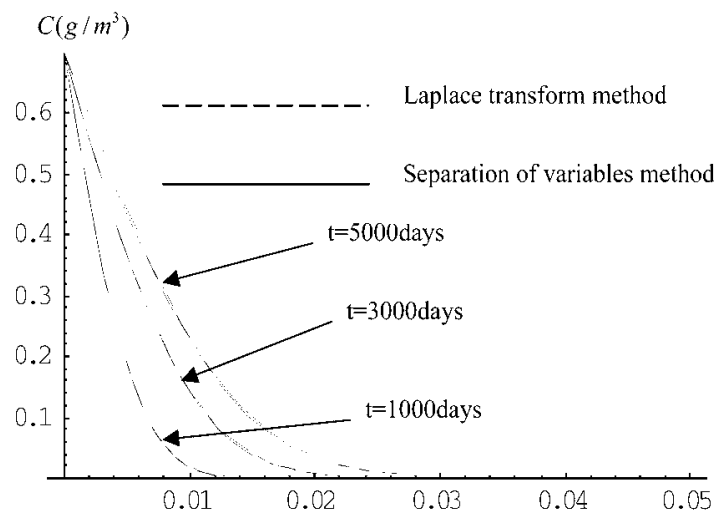

$x(m)$

Fig. 9. Relation between concentration and carbonation depth at $D_{s}=$ $10^{-13} \mathrm{~m}^{2} / \mathrm{s}$.
Equation (78) may be written as [20]

$$
x=K \sqrt{t}
$$

where $K=\sqrt{4 D_{s}} \operatorname{erfc}^{-1}\left(\frac{C-C_{i}}{C_{s}-C_{i}}\right)$.

An empirical formula for the natural concrete carbonation process was established by $\mathrm{Ju}$ [14] and is expressed as

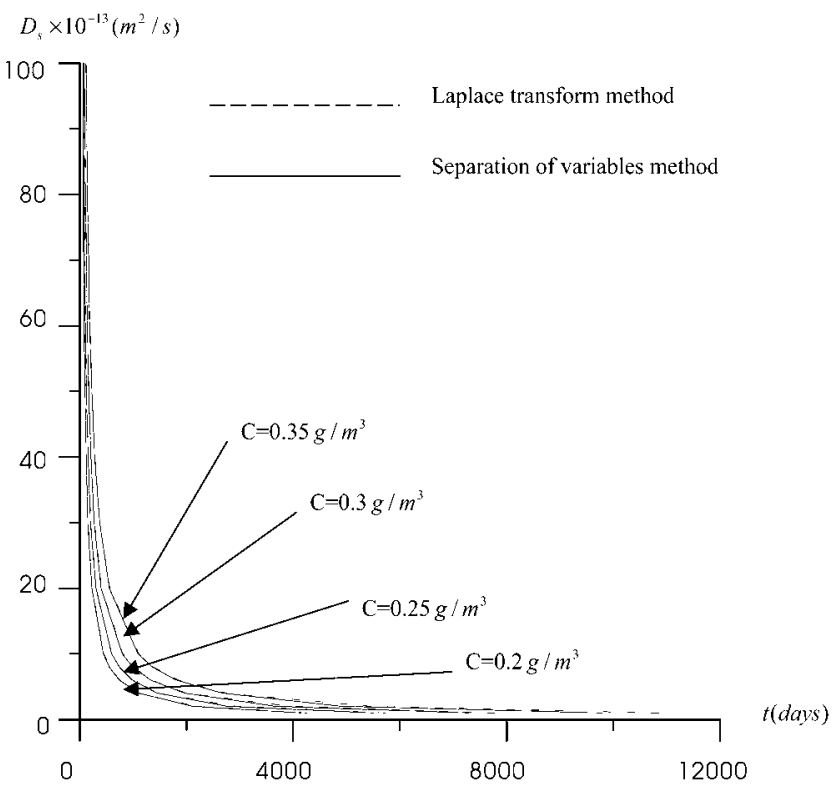

Fig. 10. Diffusion coefficient-time relationships at $x=0.04 \mathrm{~m}$.

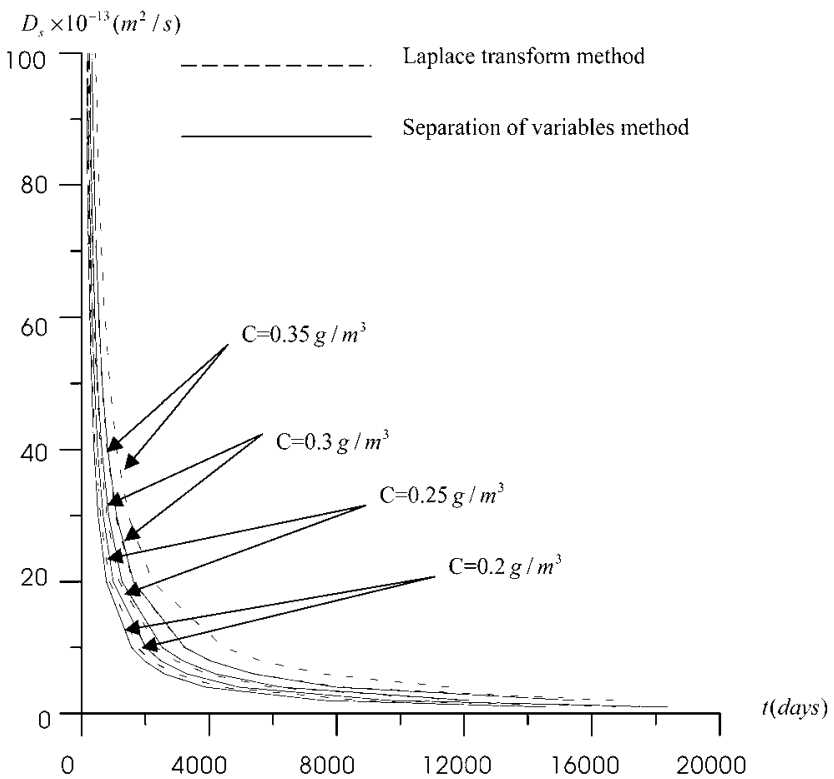

Fig. 11. Diffusion coefficient-time relationships at $x=0.02 \mathrm{~m}$. 
Table 2. Concrete carbonation depth experimental results [39]

\begin{tabular}{|c|c|c|c|c|c|c|c|}
\hline & \multirow{2}{*}{$\begin{array}{c}\begin{array}{c}\text { Carbonation } \\
\text { depth }(\mathrm{mm})\end{array} \\
\text { cement content } \\
\left(\mathrm{kg} / \mathrm{m}^{3}\right)\end{array}$} & \multicolumn{5}{|c|}{ concrete exposure time $\mathrm{t}$ (years) } & \multirow[b]{2}{*}{30} \\
\hline $\begin{array}{c}\text { water-cement } \\
\text { ratio } \frac{W}{C^{\prime}}\end{array}$ & & 5 & 10 & 15 & 20 & 25 & \\
\hline \multirow[t]{2}{*}{0.40} & $C^{\prime}=450$ & 2.73 & 3.86 & 4.73 & 5.46 & 6.11 & 6.69 \\
\hline & $C^{\prime}=400$ & 3.06 & 4.32 & 5.29 & 6.11 & 6.84 & 7.83 \\
\hline \multirow[t]{2}{*}{0.45} & $C^{\prime}=400$ & 4.18 & 5.92 & 7.24 & 8.37 & 9.37 & 10.25 \\
\hline & $C^{\prime}=350$ & 4.75 & 6.72 & 8.22 & 9.47 & 10.63 & 11.64 \\
\hline \multirow[t]{2}{*}{0.50} & $C^{\prime}=350$ & 6.03 & 8.53 & 10.45 & 12.07 & 13.49 & 14.77 \\
\hline & $C^{\prime}=325$ & 6.47 & 9.15 & 11.21 & 12.95 & 14.47 & 15.86 \\
\hline \multirow[t]{2}{*}{0.55} & $C^{\prime}=325$ & 7.85 & 11.10 & 13.59 & 15.69 & 17.55 & 19.22 \\
\hline & $C^{\prime \prime}=300$ & 8.47 & 11.98 & 14.68 & 16.94 & 18.94 & 20.74 \\
\hline \multirow[t]{2}{*}{0.60} & $C^{\prime}=300$ & 9.95 & 14.08 & 17.23 & 19.92 & 22.27 & 24.38 \\
\hline & $C^{\prime \prime}=275$ & 10.82 & 15.30 & 18.73 & 21.64 & 24.19 & 26.49 \\
\hline \multirow[t]{2}{*}{0.65} & $C^{\prime \prime}=275$ & 12.42 & 17.57 & 21.53 & 24.85 & 27.79 & 30.42 \\
\hline & $C^{\prime}=250$ & 13.61 & 19.24 & 23.57 & 27.21 & 30.44 & 33.32 \\
\hline
\end{tabular}

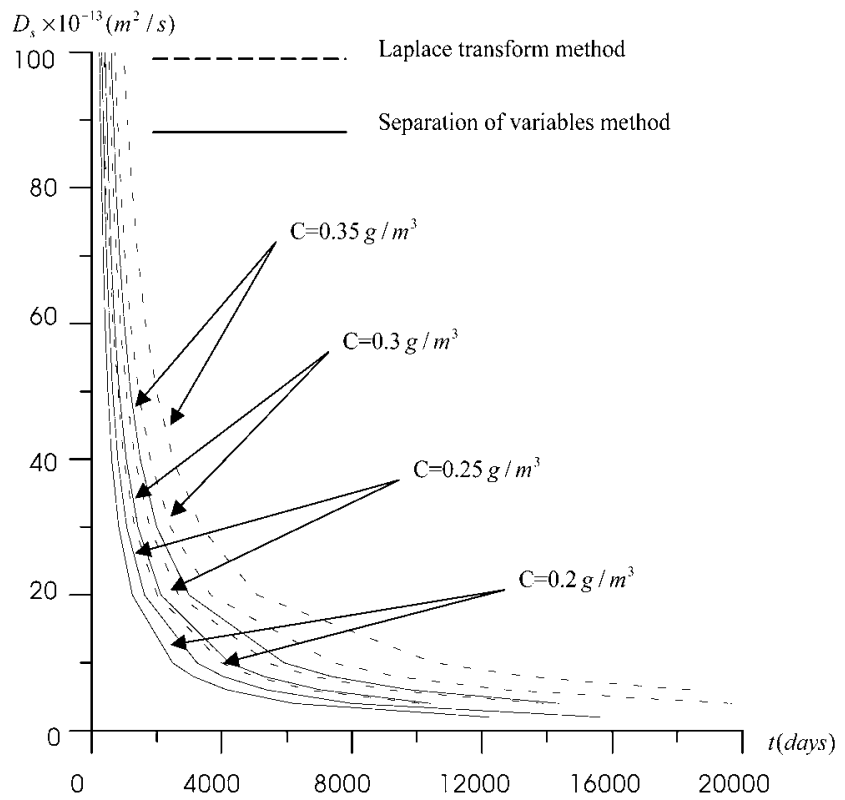

Fig. 12. Diffusion coefficient-time relationships at $x=0.03 \mathrm{~m}$.

$$
x=r_{1} r_{2} r_{3}\left(12.1 \frac{W}{C^{\prime}}-3.2\right) \sqrt{t}
$$

where $x$ is the carbonation depth ( $\mathrm{mm}), t$ is time (year), $W / C^{\prime}$ is water-cement ratio of concrete, $r_{1}$ is the cement type influence factor, which for pozzolanic cement $r_{1}=$ 1.0, and for Portland cement, $r_{1}=0.5 \sim 0.7$, and $r_{2}$ is the fly ash influence factor. If the value of the replaced cement is not larger than $15 \%$, then take $r_{2}=1.1 . r_{3}$ is the atmospheric influence factor, for a wet region, $r_{3}=$ $0.5 \sim 0.8$, and for a dry region, $r_{3}=1.1 \sim 1.2$, while between wet and dry regions, one takes $r_{3}=1.0$.
Wang [39] has applied artificial neural networks to analyze the carbonation depth of concrete and compared it with the experimental results (see Table 2). The experimental results were employed for comparing the results obtained from Eqs. (76) and (79). For Eqs. (76) and (79), $C, C_{i}, C_{s}, r_{1}, r_{2}$ and $r_{3}$ are set to $0.3 \mathrm{~g} / \mathrm{m}^{3}$, $0.0 \mathrm{~g} / \mathrm{m}^{3}, 0.7 \mathrm{~g} / \mathrm{m}^{3}$ [27], 1.0 [14, 39], 1.1, and 1.0 , respectively. These results are disclosed in Figs. 13 18. Clearly, the calculated values are in good agreement with the experimental results.

If the environment changes with time, then the surface carbon dioxide $\left(\mathrm{CO}_{2}\right)$ concentration also changes with time. To gain a relationship that permits a surface build-up of $\mathrm{CO}_{2}$, another equation may be used due to the changes in boundary conditions. The equation necessary is one that solves Eq. (77a), with the following initial and boundary conditions for a semi-infinite solid [2]:

$$
\begin{aligned}
& C(x, 0)=0 \\
& C(0, t)=\lambda(t), C(L, t)=0
\end{aligned}
$$

where $\lambda(t)$ is any function of the variable time. Though there has yet to be discovered any conclusive proof for what this function should be assigned to $\lambda(t)$, there is some intuitive support for a linear or a square root buildup of $\mathrm{CO}_{2}$ over time. For the case $\lambda(t)=\sigma t$, where $\sigma$ is a constant, the solution to Eqs. (77a), (80), and (81) simplifies to [4]:

$$
C(x, t)=\sigma t\left\{\left(1+\frac{x^{2}}{2 D_{s} t}\right) \operatorname{erfc}\left(\frac{x}{2 \sqrt{D_{s} t}}\right)-\frac{x}{\sqrt{\pi D_{s} t}} e^{-\frac{x^{2}}{4 D_{s} t}}\right\}
$$


For the case $\lambda(t)=\sigma t^{\frac{1}{2}}$, in which $\sigma$ is a constant, the solution to Eqs. (77a), (80), and (81) simplifies to [4]:

$$
C(x, t)=\sigma \sqrt{t}\left\{e^{-\frac{x^{2}}{4 D_{s} t}}-\left[\frac{x \sqrt{\pi}}{2 \sqrt{D_{s} t}} \operatorname{erfc}\left(\frac{x}{2 \sqrt{D_{s} t}}\right)\right]\right\}
$$

Equations (78), (82), and (83) are solutions to Fick's second law, Eq. (77a), which permits for a linear and a square root buildup of $\mathrm{CO}_{2}$ on the surface of a concrete structure, respectively. Equations (78), (82), and (83) assume that $D_{s}$ is constant and is independent of the concentration, time, or position. For this reason, in order to determine at what time corrosion initiates, it

$\mathrm{x}(\mathrm{m})$

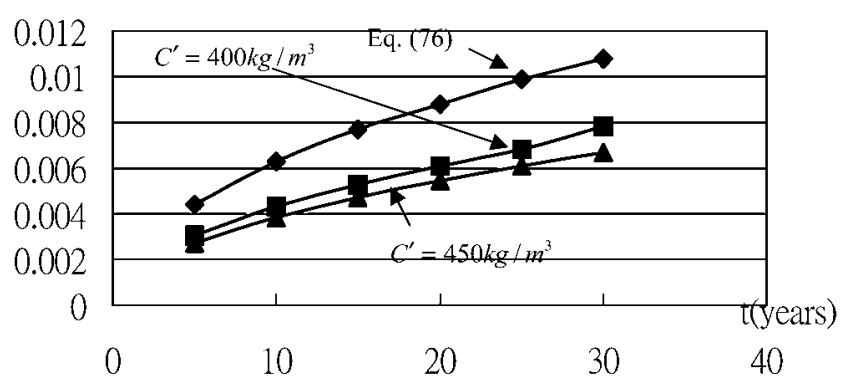

Fig. 13. Carbonation depth-time relationships at $W / C^{\prime}=0.40$.

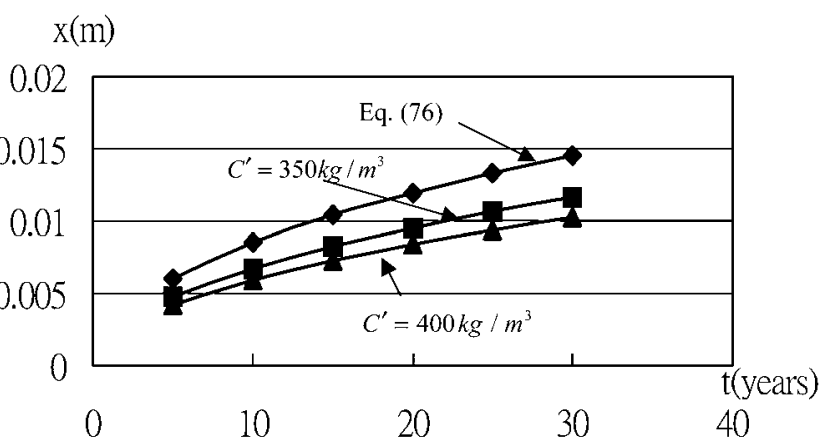

Fig. 14. Carbonation depth-time relationships at $W / C^{\prime}=0.45$.

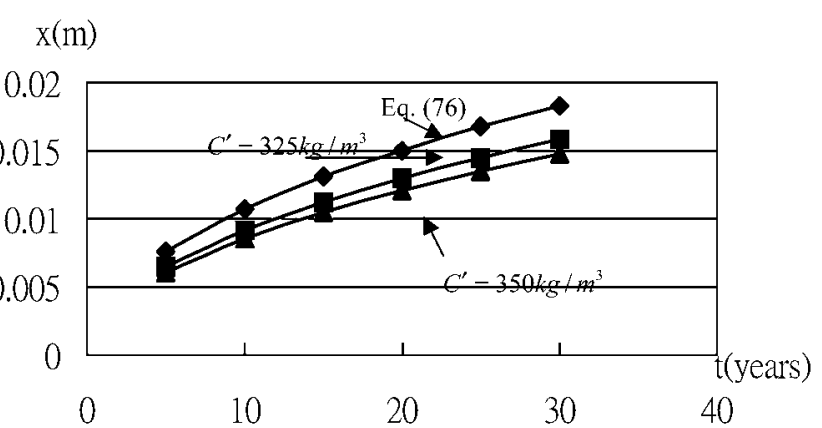

Fig. 15. Carbonation depth-time relationships at $W / C^{\prime}=0.50$. is necessary to survey or assume $D_{s}, x, C_{i}, C_{s}$, and $\lambda(t)$.

The concrete carbonation problem is described as a result of a chemical diffusion process due to $\mathrm{CO}_{2}$ penetrating into concrete. The carbon dioxide content can be predicted by means of a diffusion equation. Consider the one-dimensional diffusion equation [8] with initial and boundary conditions

$$
\begin{aligned}
& \frac{\partial C}{\partial t}=D_{s} \frac{\partial^{2} C}{\partial x^{2}}-K_{T} C \\
& C(x, 0)=C_{i} \\
& C(0, t)=C_{s}, C(L, t)=C_{f}=C_{i}
\end{aligned}
$$

$\mathrm{x}(\mathrm{m})$

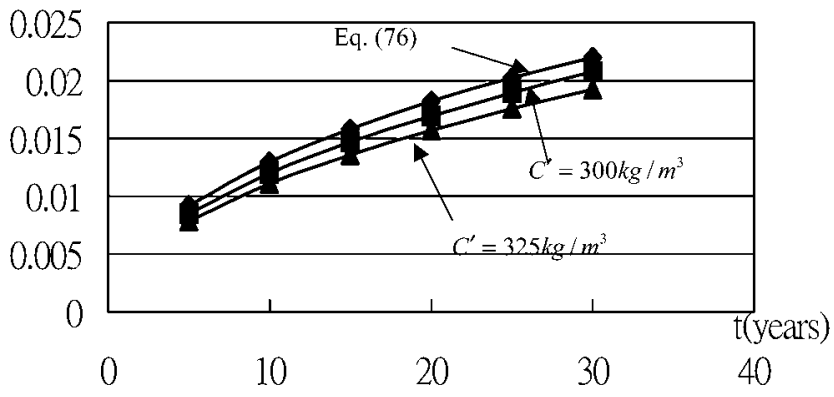

Fig. 16. Carbonation depth-time relationships at $W / C^{\prime}=0.55$.

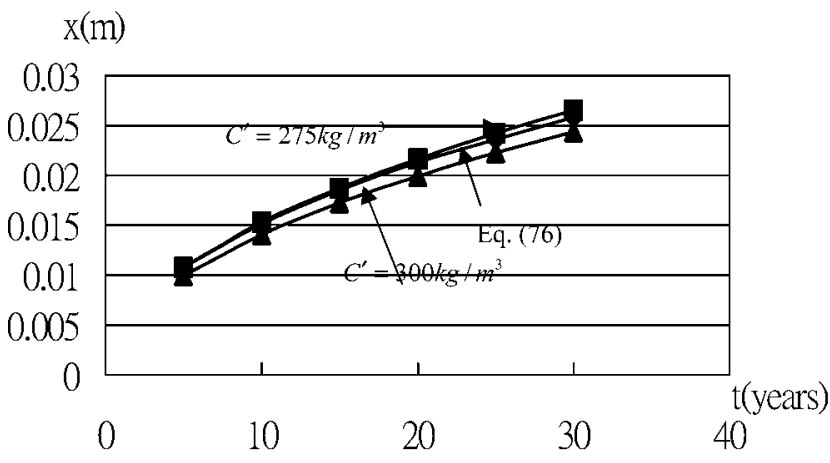

Fig. 17. Carbonation depth-time relationships at $W / C^{\prime}=0.60$.

$\mathrm{x}(\mathrm{m})$

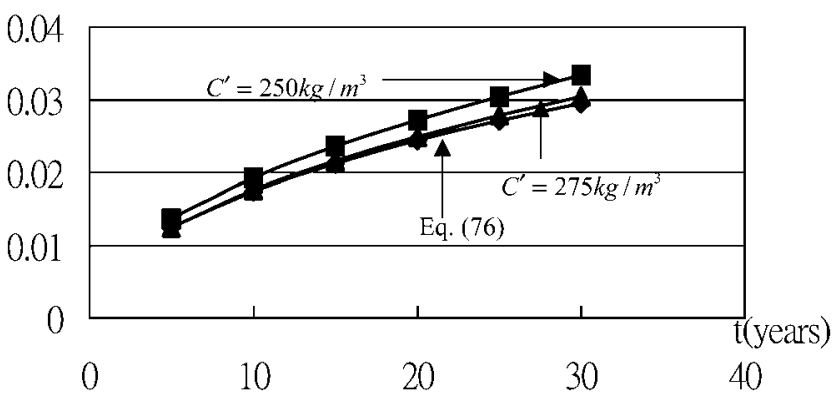

Fig. 18. Carbonation depth-time relationships at $W / C^{\prime \prime}=0.65$. 
where $K_{T}$ is a constant ${ }_{T^{t}}$

Putting $C=\bar{C} e^{-K_{T^{t}}}$ [4], where $\bar{C}$ is a new $\mathrm{CO}_{2}$ content variable, and employing the Laplace transform method to Eqs. (84a), (84b) and (84c), one obtain an analytical solution [19]:

$$
C(x, t)=\left[C_{i}+\left(C_{s} e^{K_{T} t}-C_{i}\right) \operatorname{erfc}\left(\frac{x}{\sqrt{4 D_{s} t}}\right)\right] e^{-K_{T} t}
$$

Consider the one-dimensional linear diffusion equation with initial and boundary conditions

$$
\begin{aligned}
& \frac{\partial C}{\partial t}=D_{s} \frac{\partial^{2} C}{\partial x^{2}}-v \frac{\partial C}{\partial x} \\
& C(x, 0)=C_{i} \\
& C(0, t)=C_{s}, C(L, t)=C_{f}
\end{aligned}
$$

Applying the Laplace transform method, gives the analytical solution for Eqs. (86a), (86b) and (86c):

$$
\begin{aligned}
& C(x, t)=e^{\frac{v}{2 D_{s}} x-\frac{v^{2}}{4 D_{s}} t} \int_{0}^{t} \frac{x}{2 \sqrt{\pi D_{s} \tau^{3}}} \\
& e^{-\frac{x^{2}}{4 D_{s} \tau}}\left(C_{s}-C_{i}\right) e^{\frac{v^{2}}{4 D_{s}}(t-\tau)} d \tau+C_{i}
\end{aligned}
$$

To emphasize the effects of using various equations (75), (78), (82), (83), (85) and (87), Figs. 19-22 illustrate the differences. The carbonation depth in a concrete whose carbon dioxide diffusion coefficient was determined to be $10^{-12} \mathrm{~m}^{2} / \mathrm{s}$ was plotted as a function of time in Figs. 19-22. For Eq. (75), $C_{i}, C_{s}, v$ and $K_{T}$ were set to be $0.1 \mathrm{~g} / \mathrm{m}^{3}, 0.7 \mathrm{~g} / \mathrm{m}^{3}, 10^{-12} \mathrm{~m} / \mathrm{s}$ and $10^{-10} 1 / \mathrm{s}$, respectively. For Eq. (78), $C_{i}$ and $C_{s}$ were set to be $0.1 \mathrm{~g} / \mathrm{m}^{3}$ and $0.7 \mathrm{~g} / \mathrm{m}^{3}$, respectively. For Eqs. (82) and (83), $\sigma$ was determined either assuming the linear or square root buildup. Both Eqs. (82) and (83) used $\sigma t$ and $\sigma t^{1 / 2}$ values respectively, which were forced to a maximum equivalent of $C_{s}$ after 30 years. For Eq. (85), $C_{i}, C_{s}$, and $K_{T}$ were set to be $0.1 \mathrm{~g} / \mathrm{m}^{3}, 0.7 \mathrm{~g} / \mathrm{m}^{3}$ and $10^{-10} 1 / \mathrm{s}$, respectively. For Eq. (87), $C_{i}, C_{s}, C_{f}$, and $v$ were set to be $0.1 \mathrm{~g} / \mathrm{m}^{3}, 0.7 \mathrm{~g} / \mathrm{m}^{3}, 0.2 \mathrm{~g} / \mathrm{m}^{3}$, and $10^{-12}$ $\mathrm{m} / \mathrm{s}$, respectively. From Figs. 19 22, it is obvious that Eq. (75) in general is more suitable than Eqs. (78), (82), (83), (85) and (87), which give a significant underestimation and overestimation of the carbonation depth or service life.

For illustration of Eq. (76), one draws Figs. 23-25, obtained from Figs. 1-3. From Figs. 23-25, one sees that the rate of carbonation velocity is really not constant. This shows that it is not easy to reduce Eq. (75) into Eq. (76). It is evident that Eq. (76) is not the general expression of concrete carbonation. However, from Figs. 1-3 one may express the relationship between carbonation depth and time as $[13,15]$

$$
x=a t^{b}
$$

where $a$ and $b$ are the influence coefficients. Both $a$ and $b$ depend on concrete quality and environmental factors

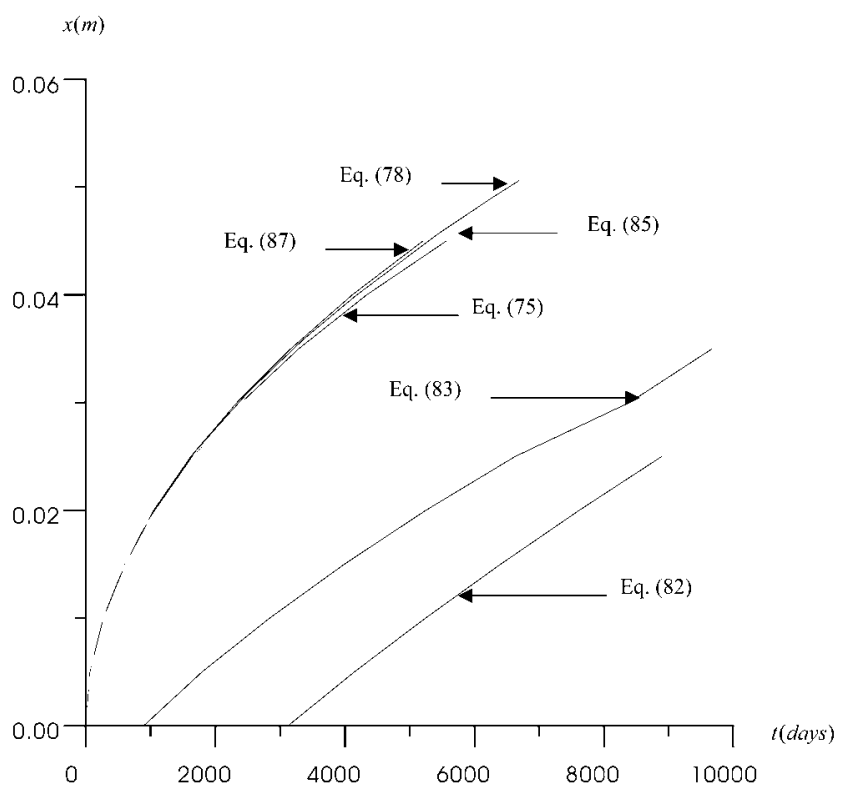

Fig. 19. Effect of using various equations [Eqs. (75), (78), (82), (83), (85), and (87)] to evaluate the carbon dioxide transport behavior in concrete of constant diffusion coefficient $D_{s}=10^{-12} \mathrm{~m}^{2} / \mathrm{s}$ and concentration $C=0.2 \mathrm{~g} / \mathrm{m}^{3}$.

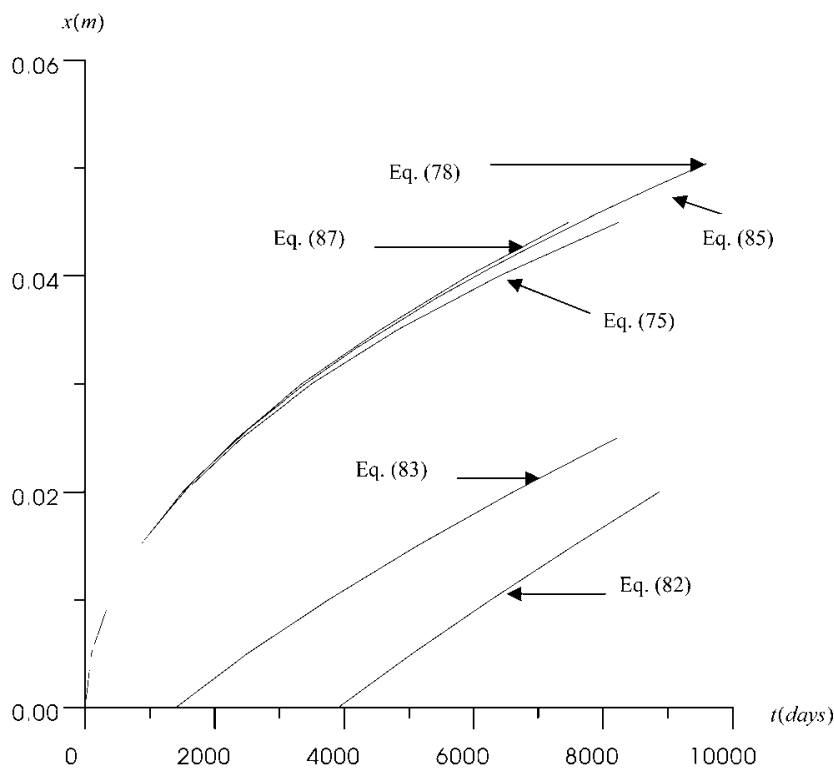

Fig. 20. Effect of using various equations [Eqs. (75), (78), (82), (83), (85), and (87)] to evaluate the carbon dioxide transport behavior in concrete of constant diffusion coefficient $D_{s}=10^{-12} \mathrm{~m}^{2} / \mathrm{s}$ and concentration $C=0.25 \mathrm{~g} / \mathrm{m}^{3}$. 
such as the diffusion coefficient, carbon dioxide concentration, temperature and relative humidity.

\section{CONCLUSIONS}

The concrete carbonation problem is one of the

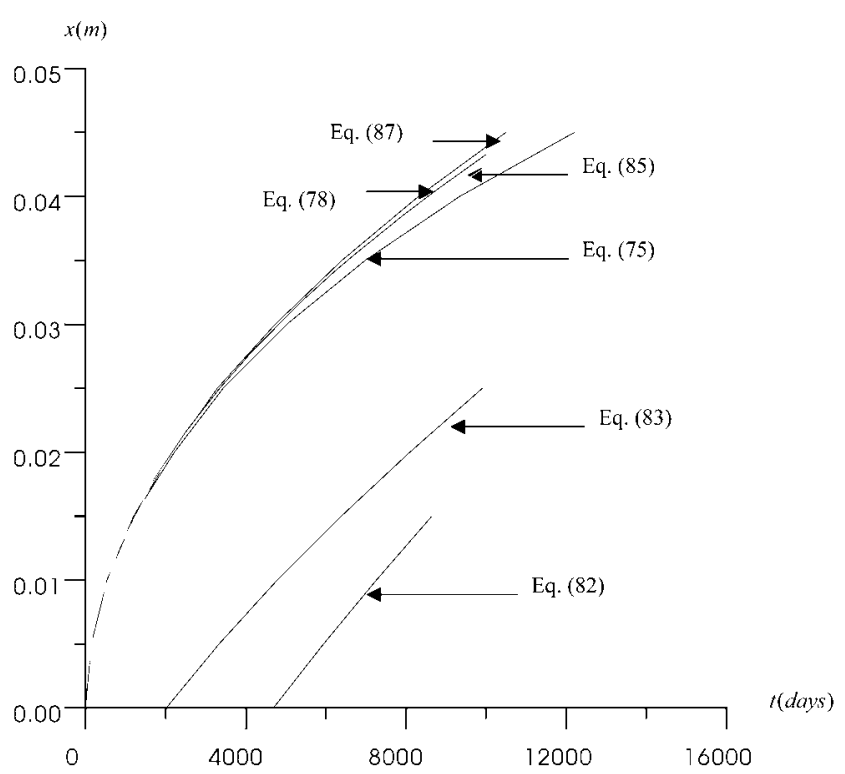

Fig. 21. Effect of using various equations [Eqs. (75), (78), (82), (83), (85), and (87)] to evaluate the carbon dioxide transport behavior in concrete of constant diffusion coefficient $D_{s}=10^{-12} \mathrm{~m}^{2} / \mathrm{s}$ and concentration $C=0.3 \mathrm{~g} / \mathrm{m}^{3}$.

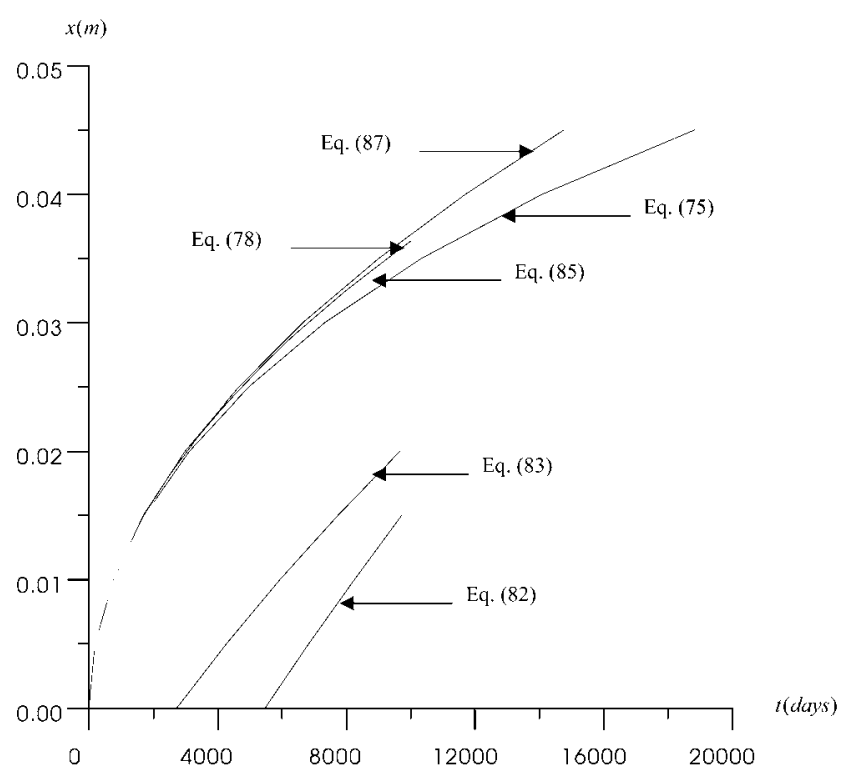

Fig. 22. Effect of using various equations [Eqs. (75), (78), (82), (83), (85), and (87)] to evaluate the carbon dioxide transport behavior in concrete of constant diffusion coefficient $D_{s}=10^{-12} \mathrm{~m}^{2} / \mathrm{s}$ and concentration $C=0.35 \mathrm{~g} / \mathrm{m}^{3}$. chemical contamination phenomena of reinforced concrete structures. The new concept of $\mathrm{CO}_{2}$ transport in concrete, a solute-transport process, has been expressed. The analytical solution for the one-dimensional convective-dispersive equation can be solved by means of the separation of variables and the Laplace transform method associated with the substitution technique. Dealing with the $\mathrm{CO}_{2}$ transport phenomena as a concrete structure carbonation process, the proposed mathematical model obtained from the Laplace transform method express more accurately the solute-transport processes

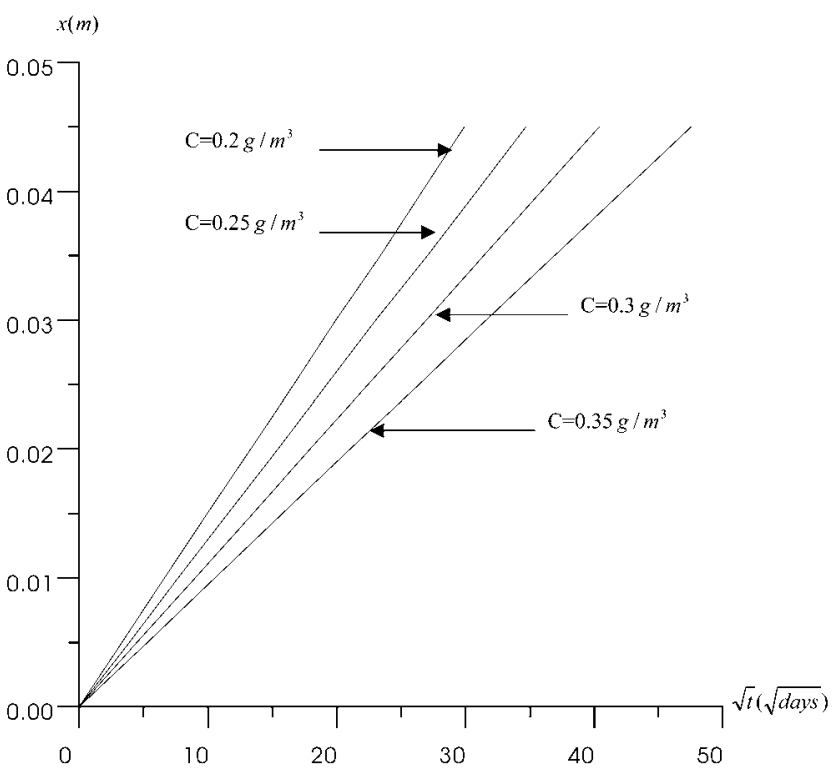

Fig. 23. Carbonation depth-time square root relationships at $D_{s}=10^{-11} \mathrm{~m}^{2} / \mathrm{s}$.

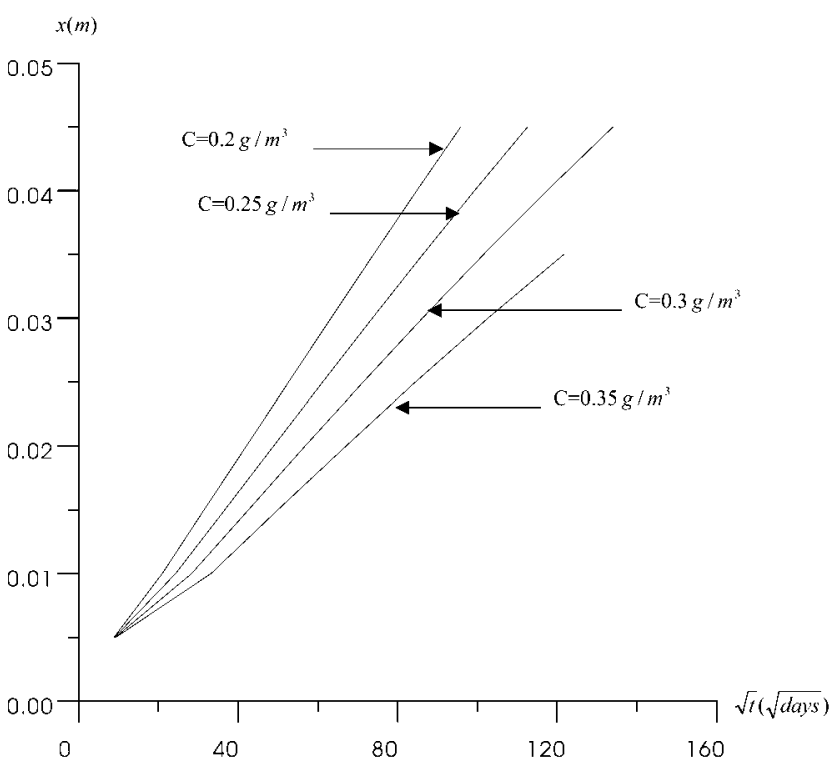

Fig. 24. Carbonation depth-time square root relationships at $D_{s}=10^{-12} \mathrm{~m}^{2} / \mathrm{s}$. 


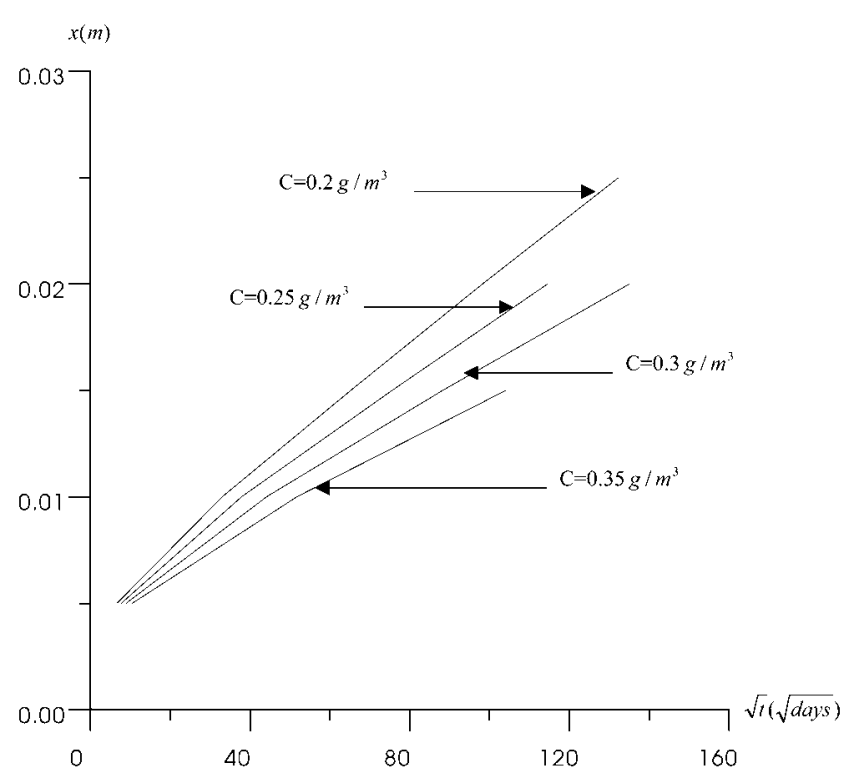

Fig. 25. Carbonation depth-time square root relationships at $D_{s}=10^{-13} \mathrm{~m}^{2} / \mathrm{s}$.

than those of both the currently used Fick's second law and the analytical solution obtained from the separation of variables method. The proposed mathematical model obtained from the Laplace transform method is suitable for treating a nonuniform diffusion system with variable parameters such as the concentration, diffusion and chemical reaction of $\mathrm{CO}_{2}$ and pore-water velocity. The relationships among concentration, carbonation depth and time that can be used to state a carbonation transport phenomena in concrete structures is examined merely by the diffusion coefficient, pore-water velocity, chemical reaction constant rate, $\mathrm{CO}_{2}$ concentration and cover thickness. However, it is suggested that experiments should be carried out for choosing suitable parameters for the numerical simulation.

\section{ACKNOWLEDGMENTS}

The authors would like to thank to the National Science Council of the R. O. C. for its financial support of this study under Contract NSC 89-2211-E-019-030.

\section{REFERENCES}

1. Abramowitz, M. and Stegun, I.A., Handbook of Mathematical Functions, $10^{\text {th }}$ Edition, Dover Publication, Inc., New York (1972).

2. Amey, S.L., Johnson, D.A., Miltenberger, M.A., and Farzam, H., "Temperature Dependence of Compressive Strength of Conversion-inhibited High Alumina Cement Concrete," ACI Materials Journal, Vol. 95, No. 1, pp. 27-36 (1998).
3. Browne, R.D., "Design Prediction of the Life for Reinforced Concrete in Marine and Other Chloride Environments," Durability of Building Materials, Vol. 1, No. 2, pp. 113-125 (1982).

4. Carslaw, H.S. and Jaeger, J.C., Conduction of Heat in Solids, $2^{\text {nd }}$ Edition, Celarendon Press, Oxford (1990).

5. Chen, S., Wang, G.T., and Xue, S.K., "Modeling BOD Removal in Constructed Wetlands with Mixing Cell Method," Journal of Environmental Engineering, Vol. 125, No. 1, ASCE, pp. 64-71 (1999).

6. Clifton, J.R., Predicting the Remaining Service Life of Concrete. U. S. Department of Commerce, National Institute of Standards and Technology, Report No. NISTIR 4712 (1991).

7. Clifton, J.R., "Predicting the Service Life of Concrete," ACI Materials Journal, Vol. 90, No. 6, pp. 611617 (1993).

8. Crank, J., The Mathematics of Diffusion, Oxford University Press, Oxford (1975).

9. Francois, R. and Maso, J.C., "Effect of Damage in Reinforced Concrete on Carbonation or Chloride Penetration," Cement and Concrete Research, Vol. 18, pp. 961-970 (1988).

10. Guirguis, S., A Basis for Determining Minimum Cover Requirement for Durability, In: Concrete Durability, ACI Detroit, Michigan (1987).

11. Hamaga, M., "Neutralization (Carbonation) of Concrete and Corrosion of Reinforcing Steel," Proceedings of $5^{\text {th }}$ International Symposium on Chemistry of Cement, Vol. 3, Tokyo, pp. 343-369 (1969).

12. Harn, Y., Jwu, T.H., and Liu, W.M., A Study of Crack Process of Concrete due to Steel Corrosion, Institute of Waterway Engineering and Science, Tenjing, Transportation Department, China (1991) (in Chinese).

13. Ju, A.M., "Studies of Concrete Carbonation and Steel Corrosion," Concrete and Building Components, Vol. 1, No. 1, pp. 18-23 (1982). (in Chinese)

14. Ju, A.M., "Concrete Carbonation and Durability of Reinforced Concrete," Concrete, Vol. 6, pp. 18-22 (1992) (in Chinese).

15. Li, Q.F., "Studies on Service Performance of Structures in Harbour Engineering," Ph. D. Dissertation, Department of Civil Engineering, Dalian University of Technology, Dalian. China (1992) (in Chinese).

16. Li, Q.F., Zhao, G.F., and Li, Y.G., "Discussion of Problems in Relation to the Structural Durability of Marine Concrete," Gangkuo Engineering, Vol. 95, pp.21-27 (1993). (in Chinese)

17. Liang, M.T., Hong, C.L., and Liang, C.H., "Service Life Prediction of Existing Reinforced Concrete Structures under Carbonation-induced Corrosion," Journal of the Chinese Institute of Civil and Hydraulic Engineering, Vol. 11, No. 3, pp. 485-492 (1999).

18. Liang, M.T., Wang, K.L., and Liang, C.H., "Service Life 
Prediction of Reinforced Concrete Structures," Cement and Concrete Research, Vol. 29, No. 10, pp. 1411-1418 (1999).

19. Liang, M.T., Zhao, G.F., Chang, C.W., and Liang, C.H., "Evaluating the Carbonation Damage to Concrete Bridges Using a Grey Forecasting Model Combined with a Statistical Method," Journal of the Chinese Institute of Engineers, Vol. 24, No. 1, pp. 85-94 (2001).

20. Maage, M., Helland, S., Poulsen, E., Vennesland, O., and Carlsen, J.E., "Service Life Prediction of Existing Concrete Structures Exposed to Marine Environment," ACI Materials Journal, Vol. 93, No. 6, pp. 602-608 (1996).

21. Mallett, G.P., State-of-the-art Review: Repair of Concrete Bridges, Thomas Telford Services Ltd., London (1994).

22. Matlab, "The Language of Technical Computing Matlab Application Program Interface Guide," Version 5, The Math Works Inc., Natick, Massachusetts (1998).

23. Nagataki, S.H., Ohga, H., and Kim, E.K., "Effect of Curing Conditions on the Carbonation of Concrete with Fly Ash and the Corrosion of Reinforcement in Longterm Tests," Proceedings of the Second International Conference on Fly Ash, Silica, Fume, Slag, and Natural Pozzolans in Concrete, ACI Sp-91, Detroit, pp. 521-540 (1986).

24. Papadakis, V.G., Vayenas, C.G., and Fardis, M.N., "A Reaction Engineering Approach to the Problem of Concrete Carbonation," American Institute of Chemical Engineering Journal, Vol. 35, No. 10, pp. 1639-1650 (1989).

25. Papadakis, V.G., Fardis, M.N., and Vayenas, C.G., "Fundamental Concrete Carbonation Model and Application to Durability of Reinforced Concrete," Proceedings of the Fifth International to Conference on Durability of Building Materials and Components (Edited by Baker, J. M., Nixon, P.J., Majumdar, A.J., and Davies H.) Brighton, U. K., pp. 27-38 (1990).

26. Papadakis, V.G., Vayenas, C.G., and Fardis, M.N., "Physical and Chemical Characteristics Affecting the Durability of Concrete," ACI Materials Journal, Vol. 88, No. 2, pp. 186-196 (1991a).

27. Papadakis, V.G., Vayenas, C.G., and Fardis, M.N., "Experimental Investigation and Mathematical Modeling of the Concrete Carbonation Problem," Chemical Engineering Science, Vol. 46, No. 5/6, pp. 1333-1338 (1991b).

28. Papadakis, V.G., Vayenas, C.G., and Fardis, M.N., "Fundamental Modeling and Experimental Investigation of Concrete Carbonation," ACI Materials Journal, Vol. 88, No. 4, pp. 363-373 (1991c).

29. Papadakis, V.G., Fardis, M.N., and Vayenas, C.G., "Ef- fect of Composition, Environmental Factors and Cement-lime Mortar Coating on Concrete Carbonation," Materials and Structures, Vol. 25, pp. 293-304 (1992).

30. Papadakis, V.G., Fardis, M.N., and Vayenas, C.G., "Physicochemical Process and Mathematical Modeling of Concrete Chlorination," Chemical Engineering Science, Vol. 51, No. 4, pp. 505-513 (1996).

31. Pommersheim, J.M. and Clifton, J.R., Models of Transport Processes in Concrete, U. S. Department of Commerce, National Institute of Standards and Technology, NISTIR 4405 (1990).

32. Qu, W.J., "Durability Evaluation and Service Life Prediction of Existing Reinforced Concrete Bridges," Ph.D. Dissertation, Southwest Chiaotung University, Shinan, Chian (1995). (in Chinese)

33. Richardson, M.G., Carbonation of Reinforced Concrete: Its Causes and Management, Citis Ltd., Dublin (1988).

34. Schiessl, P., "Zur Frage der Zulassigen Rissbreite und der Erforderlichen Betondeckung im Stahlbeto-ncan under Besonderer Berucksichtigung der Karbonatisierung des Betons," Deutscher Ausschuss fur Stahlbeton 255 (1976). (in German)

35. Tang, L.P. and Nilsson, L.O., "Rapid Determination of the Chloride Diffusivity in Concrete by Applying an Electrical Field," ACI Materials Journal, Vol. 89, No. 1, pp. 49-53 (1992).

36. Tchobanoglons, G., "Constructed Wetlands and Aquatic Plants Systems: Research, Design, Operational, and Monitoring Issues," Constructed Wetlands for Water Quality Improvement, Moshiri, G.A. Ed., Lewis Publishers, Boca Raton, Fla. pp. 23-24 (1993).

37. Tsaour, S.Y., "Calculation and Measurement of Corrosive Depth of Concrete," Concrete and Reinforcing Concrete, Vol. 1, pp. 6-10 (1989). (in Chinese)

38. Tuutti, K., Corrosion of Steel in Concrete, CBI Forskning Research, Swedish Cement and Concrete Research Institute, Stockholm (1982).

39. Wang, H.D., "Fundamental Research for Durability Evaluation of Reinforced Concrete Structures," Ph. D. Dissertation, Department of Civil Engineering, Dalian University of Technology, Dalian, P. R. China (1996). (in Chinese)

40. Weber, W.J.Jr. and DiGiano, F.A., Process Dynamics in Environmental Systems, John Wiley \& Sons, Inc., New York, pp. 423-502 (1996).

41. Wolfram Research, Inc., Mathematica User Manual, Version 3.0 (1997).

42. Wu, J.W., "Corrosion, Cracks and Safe Service of Reinforced Concrete," Concrete and Cement Production, Vol. 1, pp. 6-10 (1984). (in Chinese) 